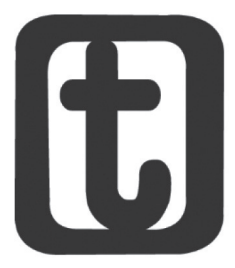

\title{
NOVO MODELO AVALIATIVO DO BPC: DESAFIOS, POSSIBILIDADES AO SERVIÇO SOCIAL
}

\author{
NEW EVALUATING MODEL IN A WELFARE PROGRAM: \\ CHALLENGES, POSSIBILITIES TO SOCIAL SERVICE
}

\section{Heloisa Helena da Silva Guedes ${ }^{1}$ Gabriela Lima Fonseca² Rubiane de Souza Ribeiro Abdo 3 Suélem Alves Santiago Donato 4 Andrea Toledo de Aguiar ${ }^{5}$ Érica Ferreira Esteves ${ }^{6}$}

1 Assistente Social do Instituto Nacional do Seguro Social - INSS, Gerência Executiva de Juiz de Fora/MG. Mestre em Serviço Social pela Universidade Federal de Juiz de Fora/MG - UFJF. formanda2002@yahoo.com.br

2 Assistente Social do Instituto Nacional do Seguro Social - INSS, Gerência Executiva de Juiz de Fora/MG. Especialista em Gestão e Planejamento Social pela Universidade Federal de Juiz de Fora/MG - UFJF. gabrielafonseca51@yahoo. com.br

3 Assistente Social do Instituto Nacional do Seguro Social - INSS, Gerência Executiva de Juiz de Fora/MG. Mestre em Serviço Social pela Universidade Federal de Juiz de Fora/MG - UFJF. rubianeribeiro@gmail.com

4 Assistente Social do Instituto Nacional do Seguro Social - INSS, Gerência Executiva de Juiz de Fora/MG. Especialista em Atendimento Integral à Família pelo Instituto Aliende da Universidade Veiga de Almeida.suelemalvessantiago@ hotmail.com

5 Assistente Social do Instituto Nacional do Seguro Social - INSS, Gerência Executiva de Juiz de Fora/MG. Graduada em Serviço Social pela Universidade Federal do Rio de Janeiro - UFRJ. andreatoledoufrj@yahoo.com.br

6 Assistente Social do Instituto Nacional do Seguro Social - INSS, Gerência Executiva de Juiz de Fora/MG. Especialista em Gestão de Sistemas e Serviços de Saúde pela Universidade Federal de Juiz de Fora/MG - UFJF. ericafesteves@ yahoo.com.br 


\section{RESUMO}

O presente artigo discute um novo viés de atuação do Serviço Social na garantia de direitos, destacando o avanço trazido pelo novo modelo de avaliação ao processo concessório do benefício assistência e evidenciando, ao mesmo tempo, os desafios e possibilidades trazidos à profissão. O Serviço Social no Instituto Nacional do Seguro Social é um serviço que visa disseminar os direitos da população em sua relação com a Previdência Social. Dentre as diversas ações, a partir de 2009, o profissional passou a atuar junto ao benefício assistencial através do Novo Modelo de Avaliação à pessoa com deficiência. Com a avaliação social associada à perícia médica adota-se uma leitura crítica da realidade ao abordar deficiência/incapacidade não por um viés restritivo/discriminatório, mas como limitação que interfere na autonomia do indivíduo nos múltiplos espaços sociais.

Palavras-chave: avaliação Social. Serviço Social. Benefício Assistencial. Direitos.

\section{ABSTRACT}

This article discusses a new trend of Social Service activity in the guarantee of rights, giving emphasis on the advancement provided by the new model of evaluating to assistance benefit concession process and, at the same time, highlighting the challenges and possibilities brought to the profession. The Social Service in National Institute of Social Security aims to disseminate rights of the people in their relation with Social Welfare. Among various actions, since 2009, social workers have performed with the assistencial benefit through the New Evaluation Model to the person with disability. With the partnership between social worker evaluation and a medical diagnostic, a critical reading of reality is adopted when approaching disability/incapacity not by a restrictive/discriminatory perspective, but as a limitation that interferes in the autonomy of the individual in multiple social spaces.

Keywords: social Evaluation. Social Service. Assistencial Benefit. Rights.

Submetido em 07/02/2012

Aceito em 08/10/2012

\section{INTRODUÇÃO}

Diante das novas demandas postas à profissão, o presente artigo objetiva discutir os desafios e possibilidades do Serviço Social na Previdência Social, a partir de sua inserção profissional no reconhecimento inicial de direito ao Beneficio de Prestação 
Continuada/BPC. Com o Novo Modelo de Avaliação à Pessoa com Deficiência, a Avaliação Social realizada nas Agências de Previdência Social (APS's) constitui-se parte do processo de concessão - antes operacionalizado apenas pela perícia médica concebendo deficiência/incapacidade não por um viés restritivo/ discriminatório, mas como limitação que interfere na autonomia nos múltiplos espaços sociais. Também se configura como nosso objetivo valorizar a política pública de Assistência Social, destacando o BPC como uma de suas frentes de atuação, bem como o trabalho do assistente social nesse processo que privilegia a análise dos aspectos socioeconômicos, ambientais e de participação social para além do prisma biologicista que reduz a saúde ao restritivo conceito de ausência de doença.

Para elaboração deste artigo, metodologicamente, as autoras utilizaram-se de fontes secundárias sobre a Previdência e Assistência Social; bem como de manuais, instruções, decretos e portarias que norteiam o trabalho do Serviço Social previdenciário e o seu processo de trabalho referente ao BPC. Para compreensão dos significantes e significados trazidos ao processo concessório pela implantação do novo modelo, o artigo conta com a contribuição das autoras em sua percepção cotidiana do (não) acesso ao benefício em suas APS, pertencentes à Gerência Executiva de Juiz de Fora - GEX/JF (Juiz de Fora, Cataguases, Leopoldina, Além Paraíba, Recreio, Palma, Carangola, Espera Feliz, São João Nepomuceno e Muriaé). Sem utilizar-se de entrevista com as profissionais, o artigo traz uma discussão acerca do ponto de vista legal através das Leis Orgânicas da Previdência Social (LOS), Assistência Social (LOAS) e dos Decretos 6214/2007, $6564 / 2008$ e 7.617/2011 sobre o Novo Modelo de Avaliação do BPC, entrelaçada com a observação qualitativa, objetiva e subjetiva do profissional que lida diretamente com uma das fases da avaliação que, conjuntamente com a análise médica determina, no tocante ao aspecto da incapacidade, o acesso ao benefício.

\section{A PREVIDÊNCIA SOCIAL BRASILEIRA E SEU PAPEL NO TRIPÉ DA SEGURIDADE SOCIAL: TECENDO ALGUMAS CONSIDERAÇÕES}

Socialmente, a Constituição Federal de 1988/CF88 trouxe uma nova percepção das políticas públicas ao instaurar o tripé da 
Seguridade Social - Saúde, Previdência Social e Assistência Social. Essas políticas ganharam um tônus de cidadania, na medida em que seus princípios e diretrizes, pautados na proteção e não no seguro social, tendem, de acordo com Marques e Mendes (2005), a ampliar a cobertura dos serviços; a dar paridade ao atendimento rural/urbano; a estabelecer a Saúde como direito universal; a destinar a Assistência Social a quem dela necessitar - sendo ambas ofertadas totalmente desvinculadas da relação contribuição-direito -; e a propagar a previdência enquanto política contributiva de base atuarial como via de sustentabilidade, preconizando a uniformidade, equivalência e irredutibilidade dos benefícios ofertados (FLEURY, 2004). Entretanto, apesar dos avanços dessas políticas, se comparada à sua operacionalização antes da CF88, a integração entre elas pouco avançou, seja pela conjuntura neoliberal de enxugamento do Estado, seja pela manutenção da fragmentação histórico-cultural das ações em que cada segmento representa uma política pública individual responsável por intervenções isoladas e sem caráter de integralidade e coparticipação que levariam o usuário a ter a dimensão das possibilidades de acesso e conquista de direitos. (MOTA, 2008).

A prova desse vácuo é observada na Saúde que, apesar de ser direito de todos e dever do Estado, desligando-se da Previdência, enfrenta problemas no acesso e na resolutividade com o sucateamento dos serviços e o crescimento da demanda reprimida. A Assistência Social, também pela demanda crescente, vê-se envolta em soluções paliativas com critérios restritos, não atingindo a população em geral, mas, sim, o segmento situado abaixo da linha de pobreza. Quanto à Previdência Social, apesar de se abrir aos segmentos antes marginalizados pela informalidade, continua dependente do mercado formal - sua maior via de arrecadação - excluindo grandes contingentes de cobertura, pois, apesar de sua contribuição não ser facultativa e sim compulsória, muitos cidadãos inseridos em atividades subalternas, de risco e mal remuneradas, não se veem em condições de arcar com a contribuição mensal que, para o contribuinte individual e/ ou facultativo, oscila entre 57,11 e $20 \%$ do salário mínimo.

7 5\% para donas de casa sem renda própria e pertencentes à famílias de baixa renda (renda familiar igual ou inferior a dois salários mínimos). 
A atual conjuntura de reestruturação produtiva e reformulação da organização do trabalho com a flexibilização/precarização através do desemprego estrutural, e o papel cada vez mais subsidiário do Estado para com as políticas sociais, atingem diretamente a Previdência, que, com uma nova proposta de reforma, se distancia do caráter universal e de cidadania amplamente preconizado pela CF88 (CARTAXO; CABRAL, 2008), tornando-se latente a correlação de forças e exigências do capital que impõem limites à vivência plena de um direito e constituindo-se em um grande desafio, inclusive, à atuação do assistente social em seu interior.

\section{O SERVIÇO SOCIAL NA POLÍTICA PREVIDENCIÁRIA: DESCORTINANDO O PAPEL DO PROFISSIONAL}

O Serviço Social é regulamentado como uma profissão liberal, porém, o profissional não detém o domínio de todos os meios para realização de seu trabalho, sendo uma parte destes providenciada através da instituição empregadora, a qual compra a força de trabalho qualificada (IAMAMOTO, 2007). No exercício de suas atribuições, enquanto trabalhador assalariado, possui uma relativa autonomia na definição de prioridades/organização de seu trabalho, interferindo indiretamente na reprodução da classe trabalhadora nos aspectos materiais e sociais. Conforme sinaliza lamamoto (2007), o trabalho centra-se, primordialmente, no campo político-ideológico, havendo a presença de um contraditório jogo de forças balizado pelos interesses do capital e do trabalho.

Yazbek (1999) considera como um desafio profissional a reinvenção de mediações capazes de articular a vida social das classes subalternas alijadas de poder, trabalho e informação, com o mundo público dos direitos e cidadania. Para a consecução de tal proposta, é primordial o fortalecimento do projeto ético-político-profissional que conquistou hegemonia no Brasil na década de 1990, o qual prevê a liberdade como valor central, comprometido com a qualidade dos serviços, e alia-se a um projeto societário de superação do capitalismo. Além disso, a análise das características assumidas pelo trabalho deve ser relacionada com as particularidades dos processos de trabalho em que se insere o assistente 
social, seja na saúde, educação, assistência social, ou na política previdenciária.

No tocante à Previdência Social, sua inserção não é contemporânea, apesar de ter ganho força a partir do concurso público ocorrido em 2008, quando, com a contratação de quase 900 profissionais (CFESS, 2010), pôde reforçar o espaço já conquistado e construir outro através da atuação no Novo Modelo de Avaliação para concessão do BPC à pessoa com deficiência.

Cronologicamente, o Serviço Social desponta neste espaço na década de 1940, a princípio como experiência piloto junto à seção de estudos e assistência social no Instituto de Aposentadorias e Pensões dos Trabalhadores do Comércio/IAPC, em meados de 1942 (SILVA, 2008). Mais tarde, a partir de 1944 com a expansão previdenciária dos Institutos de Aposentadoria e Pensões (IAPS's) - se consolida na estrutura institucional constituindo-se legalmente através da Portaria n²5/1944 do Conselho Nacional do Trabalho (CNT), bem como do Ofício $n^{\circ} 250 / 1948$. De acordo com Guimarães (2011), essa consolidação se deu de forma paulatina. O Serviço Social desenvolveu, primeiramente, seu processo de trabalho enquanto assistência complementar ${ }^{8}$ e, depois, como serviço previdenciário.

Dentre as atribuições em suas primeiras inserções na Previdência Social, coube orientar o cidadão para acesso aos benefícios; facilitar a obtenção de documentos; realizar visitas domiciliares; encaminhamentos para a rede e estudos de caso, especialmente os identificados como desajustamento sociocomportamental (IAMAMOTO; CARVALHO, 2005). Segundo Silva (2008), dada a natureza da atuação, o setor foi criado para educar o usuário frente às prerrogativas institucionais, contribuindo para o ajustamento social e para a diminuição do comportamento desviante.

Com o advento da Lei Orgânica da Previdência Social/ LOPS - Lei $n^{\circ} 3.807 / 1960$, o Serviço Social, enquanto assistência

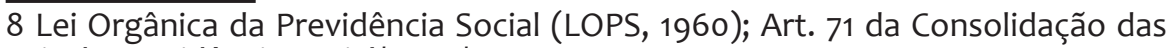
Leis da Previdência Social/CLPS/1976.

9 Art. 88, Lei n 8.213/1991; Matriz Teórico-Metodológica do Serviço Social/1994. 
complementar, consolida as funções de orientação dos serviços, benefícios e o acompanhamento individual/grupal dos beneficiários (CATARXO, 1995). De acordo com a LOPS em seus artigos 22 e 52 (BRASIL, 1960), os serviços/benefícios disseminados pelo Serviço Social seriam acessados de acordo com o perfil do pleiteante: benefícios pecuniários para segurados e seus dependentes em situação de doença, invalidez, aposentadoria, pensão por morte; e, aos demais trabalhadores filiados, assistências médica, alimentar, habitacional, reeducação e readaptação profissional, além da assistência complementar através da ação educativa, em que o Serviço Social buscaria a melhoria das condições de vida e a conscientização dos direitos e deveres através de condutas saudáveis. (GUIMARÃES, 2011).

A partir de 1965, para intensificar o trabalho profissional, normas gerais foram criadas com a Resolução $n^{\circ} 1081$ do Conselho Diretor do Departamento Nacional de Previdência Social (DNPS, 1965), delineando a atuação notadamente nos setores de benefícios, assistência médica, financeira e pessoal, ainda sob uma postura de prevenção/correção de desvios por meio da atuação direta na família, no trabalho e na comunidade (GUIMARÃES, 2011), premissa reforçada também pelo Regulamento Geral da Previdência Social de 1973, que norteou o trabalho na década de 1970 , reiterando a conduta da ajuda pessoal nos casos de desajustamento e revelando a permanência de uma prática tradicional a partir do referencial funcionalista. (SILVA, 2010).

Apesar do Serviço Social ainda na década de 1960 ter engendrado um movimento para reflexão de sua prática conhecido como "Movimento de Reconceituação", buscando romper com a postura tradicional de inspiração norte-americana que não condizia com a realidade sócio-histórica brasileira (AGUIAR, 1982), pela conjuntura em que a profissão se insere na estrutura previdenciária e pela conformação das demandas atribuídas pela Instituição, o processo de trabalho do assistente social nos anos 70 e 80 neste espaço socioocupacional permaneceu muito adequado às premissas do capital que necessitava de força de trabalho produtiva e saudável, sem desajustes. 
Para Netto (2007), a perspectiva modernizadora presente no "Movimento de Reconceituação" revelou a reiteração da ordem sociopolítica do pós 64 e a ação do Serviço Social continuava a corresponder aos apelos de adequação da sociedade. Como aponta Faleiros (2008), no Instituto Nacional de Previdência Social (INPS), o Plano Básico de Ação do Serviço Social I estabelecido pela Resolução $n^{\circ}$ 401.4/INPS/1972 previa que as ações profissionais deveriam basear-se nos objetivos do Instituto, finalidades da profissão e necessidades dos beneficiários. Logo, ao profissional, caberiam ações político-pedagógicas de enfoque assistencialista, reduzindo a "questão social" em expressão psicossocial, legitimando o individualismo na busca de respostas às necessidades mais prementes (ABREU; LOPES, 2008). Mesmo com o II Plano Básico de Ação do Serviço Social em 1978, a atuação continuou na mesma linha, ainda que defendesse uma postura "abrangente" na busca da integração social do usuário com o meio em que vive. De acordo com Pereira (2006), o Serviço Social previdenciário nas décadas de 1970 e 1980, ao preconizar ações adaptativas para que o indivíduo vivesse em harmonia com o seu ambiente, adequando-se às normas dos serviços prestados, e atendesse às demandas do capital, na verdade, reforçou a concepção moral e de ajuda e não a via de acesso a direitos.

O profissional passa a atuar mais centrado no interesse coletivo com os novos rumos da política previdenciária, impulsionados pelos ditames da CF88 (CFESS, 1993). Com a lei n 8.213/1991 determinando os Planos de Benefícios da Previdência Social, há o entendimento do Serviço Social como serviço que trabalhará junto aos usuários, esclarecendo os direitos e meios de acesso, além da corresponsabilidade na busca de soluções no embate surgido entre previdência-cidadão e demais instâncias da sociedade (CATARXO, 2010).

Nos anos 1990, há a identificação do fortalecimento do Serviço Social com uma atuação voltada à informação/orientação previdenciárias, à realização de estudo e à emissão de parecer social, à articulação com as instituições da sociedade civil para disseminação de direitos o que, segundo Catarxo e Cabral (2008), revelou uma profissão realmente voltada para os interesses da classe trabalhadora. A postura mais emancipatória ao trabalhar 
com o antagonismo existente entre capital e trabalho e a "questão social", advinda desse conflito e não por vontade pessoal, ganhou reforço com os preceitos da Lei de Regulamentação da Profissão e do Código de Ética do Assistente Social, ambos de 1993, bem como das Diretrizes Curriculares da Associação Brasileira de Estudo e Pesquisa em Serviço Social (ABEPSS) a partir de 1996. Em 1994, o Serviço Social conquistou, no interior do agora Instituto Nacional do Seguro Social (INSS), sua maturidade teórico-prática, a partir da Matriz Teórico-Metodológica (MOREIRA, 2008) com a adoção dos princípios de cidadania, direito e participação coletiva (BRASIL, 1994), se opondo à postura tradicional/funcionalista que marcou as ações nas décadas anteriores, abarcando o método crítico-dialético, resultando no entendimento da Previdência Social como um direito e não benesse. (CARTAXO; CABRAL, 2008).

O início dos anos 1990 foi importante para a consolidação do Serviço Social enquanto profissão comprometida com os trabalhadores no âmbito previdenciário. Entretanto, também foi a década em que essa área enfrentou os rebatimentos da reestruturação do Estado, fruto da concepção neoliberal adotada, primeiro, por Fernando Collor e, depois, por Fernando Henrique Cardoso. De acordo com Behring (2003), a Reforma do Estado teve como consequência direta, na Previdência Social, a queda vertiginosa de sua cobertura, prejudicando o acesso. Além disso, o próprio Serviço Social teve sua efetividade questionada, a ponto da Medida Provisória n $1729 / 1998$ extingui-lo dos quadros e, somente por força da mobilização da categoria capitaneada pela Divisão de Serviço Social (DSS) e das instâncias da sociedade civil, reverteu-se a situação, assegurando a permanência dos assistentes sociais. Em 1999, o setor sofre novo ataque, agora com a extinção da própria DSS via Decreto $n^{\circ} 3.081$, forçando a categoria a se mobilizar mais uma vez na defesa de seus interesses e na manutenção da DSS, importante órgão de regulação da profissão no âmbito da previdência.

Diante do movimento de desconstrução do Serviço Social previdenciário ocorrido especialmente nos últimos anos da década de 1990, em que a profissão regride de serviço a atividade auxiliar, os anos 2000 representaram a retomada do seu espaço sócio-ocupacional enquanto um serviço voltado aos interesses 
da população. Não diferente dos anos 1990, a primeira década dos anos 2000 foi permeada por fortes ataques aos direitos dos trabalhadores, como o caso da Reforma da Previdência de 2003. O Serviço Social percebe, então, através da emissão da Portaria Interministerial $\mathrm{n}^{\circ}$ 01/2007, elaborada pelos Ministérios da Previdência e Desenvolvimento Social-MPS/MDS, que a criação do Grupo de Trabalho (GT) seria um forte aliado para a reestruturação do serviço - com a definição de competências, atribuições, possibilidades mais amplas de atendimento à população demandante, ampliação do quadro profissional, dentre outros -, uma vez que houve uma abertura à participação não apenas dos dois ministérios, mas também do Conselho Federal de Serviço Social (CFESS) (SILVA, 2010).

A partir das novas discussões sobre a atuação do Serviço Social via GT, ao final da primeira década dos anos 2000, com a publicação do Decreto $n^{\circ} 6.214 / 2007$, a profissão teve sua atuação fortalecida ao ser requisitada a participar do processo concessório do $\mathrm{BPC}$, voltado à pessoa com deficiência que, ainda que não seja benefício previdenciário, é operacionalizado pelo INSS. Essa nova frente de trabalho exigiu o olhar social na conformação da incapacidade/limitação, desencadeando a urgência em repor os quadros da previdência com o profissional de Serviço Social.

\section{O PROCESSO DE TRABALHO DO ASSISTENTE SOCIAL NO INSS: CONCEBENDO A PRÁTICA NA PERSPECTIVA DO DIREITO}

O Serviço Social caracteriza-se como um serviço prestado aos segurados, dependentes e demais usuários da Previdência Social, competindo-lhe esclarecer os direitos e os meios para exercê-los. Seu processo de trabalho se dá através de um conjunto de ações alocado em três eixos: a socialização das informações previdenciárias e assistenciais, processo de educação previdenciária que dissemina os condicionantes para acesso aos benefícios previdenciários e assistenciais via atendimentos individuais/grupais intra e extrainstitucionais. A assessoria/consultoria publiciza a dinâmica previdenciária, fomentando profissionais, movimentos sociais, instituições governamentais e não governamentais para elaboração de propostas e implementação de melhorias na área em interface com outras políticas. A Assessoria se configura em 
ação contínua/sistemática através da troca de saberes. A consultoria, ação pontual, envolve a produção de projeto, relatório, etc que serão desenvolvidos pelos demandantes (INSS/DIRSAT, 2012). O fortalecimento do coletivo fomenta a análise/compreensão dos condicionantes que permeiam sua relação com a Previdência de forma a lutarem pela ampliação de seus direitos e acesso (INSS/ DIRSAT, 2012). Para realização dessas ações, várias estratégias e técnicas são adotadas, como entrevistas, domínio da legislação social, estudo da realidade e detecção de prioridades, planejamento de atividades socioeducativas, espaços de discussão coletiva, dentre outras.

Baseadas nesses três eixos de atuação, suas atribuições são norteadas por três diretrizes, denominadas "Linhas de Ação": Ampliação e Consolidação do acesso à Previdência Social; Segurança e Saúde do Trabalhador; Direitos das Pessoas com Deficiência e das Pessoas Idosas. Essas diretrizes, por sua vez, agregam vários projetos de intervenção, como os voltados para o atendimento Geral ao Usuário (AGU), o Benefício Assistencial, Saúde do Trabalhador, Trabalhador Rural e Pensão por Morte (INSS/DIRSAT, 2012). Na consecução dessas linhas, são utilizados como instrumentais "a linguagem e o conhecimento técnico; o parecer social, o parecer técnico fundamentado, a visita domiciliar/hospitalar, a pesquisa social e o cadastro das organizações da sociedade." (INSS/ DIRSAT, 2012).

A linguagem e o conhecimento técnico estabelecem o conteúdo das orientações/informações que são disseminadas através da relação dialógica entre profissional/usuário. O parecer social e o parecer técnico fundamentado, requisitados pelos diversos setores do INSS, pela Procuradoria Federal ou mesmo pelo próprio assistente social em situações específicas (como na concessão, manutenção, recurso, embasamento da decisão pericial, bem como na caracterização das situações de união estável e dependência econômica), são o pronunciamento profissional baseado em estudo social. Terão acesso aos referidos pareceres os setores demandantes e o estudo social, de caráter sigiloso, ficará sob a guarda do Serviço Social em arquivo próprio. A visita domiciliar/ hospitalar possibilita a visão in loco de suas condições de vida e saúde. A pesquisa social propicia o aprofundamento e renovação 
do conhecimento, fomentando o profissional a trabalhar mais próximo da realidade social em que vive a população demandante. O cadastro das organizações da sociedade possibilita conhecer a rede para a qual os usuários serão encaminhados, visando à garantia de direito e acesso às demais políticas públicas. (INSS/ DIRSAT, 2012).

No processo de trabalho inscrito nas três linhas de ação, busca-se a análise crítica da realidade, pois, como apontam Cartaxo e Cabral (2008), faz-se necessária a compreensão das transformações socioculturais geradas pela crise do capital, uma vez que trazem rebatimentos tanto à vida dos usuários quanto ao fazer profissional através da precarização das condições de trabaIho e da redução do papel do Estado perante os direitos sociais, principalmente no que se refere aos trabalhistas e previdenciários. Essa realidade reflete nas demandas individuais/coletivas do Serviço Social, uma vez que os usuários desprotegidos e alijados dos mínimos sociais necessitam recorrer às políticas públicas de previdência e assistência social para a satisfação de suas necessidades básicas. (BRAGA; CABRAL, 2008).

No que se refere à intervenção junto aos benefícios da Assistência Social, mesmo atuando no espaço sócio-ocupacional no INSS, o Serviço Social conquista importância salutar com a Avaliação Social no processo de concessão do BPC, imposta pelo Decreto 6214/2007. Ao ter a sua atuação junto ao benefício assistencial como etapa obrigatória, o profissional percebeu a oportunidade de fazer a interlocução entre as políticas que compõem a Seguridade Social, não ficando restrito à questão previdenciária. O intercâmbio entre as principais políticas de proteção tornou-se importante seleiro de discussão e atuação para a profissão frente às novas conformações do direito ao BPC, que passou a ser concedido sobre novos parâmetros de deficiência/incapacidade.

\section{CAMINHOS E DESCAMINHOS DO BPC: DO ACESSO ANCORADO NA PERSPECTIVA BIOMÉDICA AO NOVO MODELO DE AVALIAÇÃO SOCIAL}

Para Pereira (2006), a Assistência Social percorreu um longo caminho até se transformar em política pública com status de direito social garantido constitucionalmente. Uma de suas 
expressões, o BPC revisto a cada dois anos para verificação da continuidade das condições que lhe deram origem, constitui-se numa estratégia de transferência de renda a idosos e deficientes situados na classe pobre, conjugando idade (idoso a partir de 65 anos), saúde (deficiente com limitação/incapacidade de longo prazo, igual ou superior a dois anos), e renda per capita inferior a $1 / 4$ do salário mínimo vigente aferida do somatório das rendas (in)formais do grupo familiar e da divisão desse total entre seus membros, ressalvado o contido na Ação Civil Pública $n^{\circ}$ 2009.38.00.005945, explicitada no Memorando Circular Conjunto $\mathrm{n}^{\circ} 31$ DIRBEN/PFE/INSS ${ }^{10}$ de 06 de julho de 2012, em que, na jurisdição do Estado de Minas Gerais, desconsidera-se outro BPC e os benefícios previdenciários de valor mínimo. O conceito de família adotado é o nuclear, composto em relação ao requerente por: pais, esposo(a), companheiro(a), filhos e irmãos solteiros de qualquer idade; excluindo-se filhos e irmãos casados legalmente, avós, tios e afins.

Até a implantação definitiva do BPC, em 1996, a assistência social ao deficiente e ao idoso no Brasil se dava de forma pulverizada/descontínua e se apresentava como assistencialista-caritativa. De acordo com Silva (2010), aportado em Sposati (2008), com o BPC, o país inaugura um sistema de proteção social de massa, a partir da concessão de um benefício sem a contrapartida da contribuição, devendo ser integrado às demais políticas setoriais para um efetivo combate à pobreza e à exclusão. Com o BPC, a Assistência Social passou a ser compreendida em seu potencial de universalização e direito, se comparada às suas ações anteriores de benesse e culpabilização do usuário. Entretanto, ainda que o benefício tenha alçado essa política a outro patamar, permaneceu restritivo/excludente ao se dirigir àqueles incapazes de prover sua subsistência, dada a necessidade de enquadramento no critério de renda (GOMES, 2008).

Para operacionalização do BPC, coube a participação da Previdência Social, incumbida de habilitar e avaliar os requerimentos em face de sua experiência com a concessão de outros

10 Diretoria de Benefícios, Procuradoria Federal, Instituto Nacional do Seguro Social. 
benefícios e sua infraestrutura (SILVA, 2010). Na atualidade, além da LOAS, três Decretos regulamentam o BPC: o 6214/2007, o 6564/2008 e o 7617/2011. O primeiro determina, dentre outras prerrogativas: um novo modelo de avaliação, mesclando aspectos biológicos e sociais e utilizando a Classificação de Incapacidade e Funcionalidade em Saúde (CIF) e não a Classificação Internacional de Doenças (CID10); a não suspensão do recebimento ao segurado em habilitação/reabilitação; a possibilidade de restauração do benefício aos que pediram sua suspensão para retorno ao mercado de trabalho; o acesso à pessoa em situação de rua. Alterando e complementando o disposto, os Decretos 6564/2008 e 7617/2011 determinam, dentre outras: a permissão de acúmulo do BPC com benefícios da assistência médica e as pensões especiais indenizatórias; a diferenciação nas avaliações de crianças e adolescentes menores de 16 anos, não levando em consideração a incapacidade para o trabalho como procedido em maiores de 16; o acesso ao brasileiro naturalizado.

Dentre as diversas mudanças trazidas pelos Decretos supracitados, sem dúvida a inclusão do enfoque social foi o mais representativo avanço, na medida em que a incapacidade/limitação deixou de ser apreendida como característica individual e torna-se objeto de estudo voltado à realidade social.

De 1993 até meados de 2009, os critérios utilizados pelos peritos (únicos até então habilitados à avaliação) verificavam os graus da deficiência através do conceito adotado pelo Decreto 1744 (BRASIL, 1995), concebendo o deficiente como incapaz para a vida independente e para o trabalho, devido à anomalias/lesões irreversíveis, espelhando o modelo médico-hegemônico pautado na doença e não nos determinantes sociais.

Historicamente, a deficiência foi analisada sobre o prisma do estigma (DINIZ; SQUINCA; MEDEIROS, 2007), enquanto esfera individual e não como produto das péssimas condições de vida, da falta do sentimento de pertença e do pouco acesso aos cuidados e serviços de saúde. No modelo atual de avaliação, o conceito tradicional revelou-se insatisfatório para determinar a incapacidade, porque as restrições cognitivas para trabalho e vida cotidiana nem sempre estão no indivíduo, mas na interação que o mesmo 
estabelece com o meio, demarcando a vulnerabilidade e a existência de barreiras objetivas/subjetivas ao bem-viver para além do aspecto físico/biológico determinado pelas aptidões visuais, auditivas, de locomoção e fala. Assim, a partir de 2009, passou-se a adotar o conceito de deficiência trazido pelo Decreto 6214/2007 e consubstanciado na CIF de "[...] problema nas funções ou nas estruturas do corpo com um desvio importante ou perda [...]" (OMS, 2008), determinando que funcionalidade e incapacidade são resultantes da interação entre estados de saúde, meio ambiente e participação.

Com a promulgação do Decreto n 6214/2007 e atualizações posteriores, foram instituídos os instrumentos para avaliação da deficiência e do grau de incapacidade de pessoas com deficiência, sendo os mesmos compostos de avaliação médica e social. A partir da Portaria Conjunta MDS/INSS n 1/2009, atualizada pela Portaria Conjunta MDS/INSS $n^{\circ} 1$, de 24/2011, os instrumentos utilizados pelo assistente social para a Avaliação Social, voltados ao menor de dezesseis anos (criança e adolescente) e aos com dezesseis anos ou mais, contemplam os domínios "Fatores Ambientais" e "Atividade e Participação-parte social". Para avaliação dos Fatores Ambientais, são analisados, a partir dos qualificadores de barreira, os ambientes social (relações de convívio familiar, comunitário e social, considerando a acessibilidade às políticas públicas, a vulnerabilidade e o risco pessoal e social a que a pessoa com deficiência está submetida) e físico (território onde vive e as condições de vida presentes, considerando a acessibilidade, salubridade ou insalubridade). No que se refere ao domínio Atividade e Participação-parte social, são utilizados os qualificadores de dificuldade, considerando o impacto/influência dos fatores ambientais na avaliação do desempenho para atividades (compreendida enquanto execução de uma tarefa/ação) e participação (o ato de se envolver em uma situação real de vida).

Através do amplo instrumento de avaliação, no novo modelo, o fenômeno da incapacidade passa a ser entendido também como resultante da maneira como a sociedade se organiza, não sendo mais apreendida como atributo da pessoa, mas como fruto das situações vivenciadas no contexto socioambiental (GUEDES; NOGUEIRA; CAMARGO, 2006). Logo, passam a ser 
consideradas as necessidades humanas personificadas nas diferentes dimensões da saúde (biológica, individual e social) que permitem uma visão de totalidade (PEREIRA, 2008), sendo a incapacidade para a vida independente e trabalho entendida nos seus múltiplos aspectos (CAVALCANTI et al, 2009). Nessa nova perspectiva, de acordo com as Portarias Conjuntas MDS/INSS ${ }^{11} \mathrm{n}^{\circ}$ 01/2009 e $n^{\circ}$ 01/2011, cabe ao Serviço Social considerar e qualificar: a) os fatores ambientais por meio dos domínios: produtos e tecnologias; condições de moradia e mudanças ambientais; apoios e relacionamentos; atitudes; serviços, sistemas e políticas; b) a atividade e participação-parte social, para requerentes com 16 anos de idade ou mais, por meio dos domínios vida doméstica; relação e interações interpessoais; áreas principais da vida; vida comunitária, social e cívica; c) a atividade e participação-parte social, para requerentes menores de 16 anos, por meio dos domínios relação e interações interpessoais; áreas principais da vida; vida comunitária, social e cívica. Sob esse prisma, a análise volta-se à leitura da realidade socioeconômica-política e cultural dos indivíduos, a partir dos fatores ambientais, sociais e pessoais.

À perícia médica fica a incumbência de analisar a "Função/ Estrutura do Corpo" e a "Atividade e Participação-parte médica", determinando se o quadro apresentado redunda em um comprometimento de longo prazo. No caso do domínio Atividade e Participação, a avaliação é compartilhada por ambos avaliadores. $O$ resultado final conforma as limitações e barreiras que podem ser enquadradas como sendo $\mathrm{N}$ - nenhuma, $\mathrm{L}$ - leve, $\mathrm{M}$ - moderado, $\mathrm{G}$ - grave, $\mathrm{C}$ - completa e, apesar das avaliações ocorrerem em separado, com cada avaliador procedendo à sua análise de acordo com suas especificidades, será o somatório das avaliações que determinará se o requerente preenche ou não os requisitos de incapacidade para a vida independente e para o trabalho (BRASIL, 2007), determinados pelo Art. 20, parágrafo $2^{\circ}$ da lei 8.742/93 (BRASIL, 1993).

11 Ministério do Desenvolvimento Social, Instituto Nacional do Seguro Social. 


\section{LIMITES E POSSIBILIDADES DO NOVO MODELO DE AVALIAÇÃO SOCIAL DA PESSOA COM DEFICIÊNCIA: O OLHAR DAS ASSISTENTES SOCIAIS INSERIDAS NAS APS PERTENCENTES À GEXJF}

Com a implantação do Novo Modelo de Avaliação, o BPC adota um viés mais amplo de proteção social das pessoas com deficiência por levar em consideração as barreiras/limitações existentes para a plena participação na sociedade, passando a questionar o quanto as condições de moradia, situações de preconceito, falta de acesso às políticas públicas bem como as dificuldades de interação social, podem influenciar na qualidade de vida. Nesse processo, o olhar crítico do assistente social revelou-se salutar na avaliação dos domínios "Fatores Ambientais e Atividade e Participação-Parte Social”, por ser esse o profissional capacitado para decifrar questões camufladas em uma sociedade permeada por desigualdades advindas do conflito capital/trabaIho (ANTUNES, 2007) que configuram a "questão social".

Os instrumentos de avaliação do BPC estão em constante aperfeiçoamento, como o promovido pelos anexos I e II do Memorando Circular Conjunto DIRSAT/DIRBEN/DIRAT/INSS ${ }^{12} \mathrm{n}^{\circ}$ 03/2011 e pela Portaria Conjunta MDS/INSS nº 01/2011, que trouxeram reformulações importantes através de questionamentos mais amplos sobre as condições de vida, saúde e acesso dos usuários, e as barreiras/dificuldades que vivenciam face à limitação/incapacidade. Entretanto, permanecem alguns limites intra e extrainstitucionais que, se equacionados, otimizariam o reconhecimento inicial de direito ao benefício. Como limite intrainstitucional, destaca-se a pouca interação com a perícia médica, não apenas no sentido de o Serviço Social proceder à leitura da realidade, mas também no que diz respeito à Medicina, que, em alguns casos, ainda se limita ao conceito de deficiência ligado apenas à função do corpo. O ideal no complexo processo de trabalho do BPC seria a discussão de situações que envolvem os determinantes sociais no processo de adoecimento; todavia, devido ao

12 Diretoria de Saúde do Trabalhador, Diretoria de Benefícios, Diretoria de Atendimento, Instituto Nacional do Seguro Social. 
número reduzido de assistentes sociais ${ }^{13}$, a indisponibilidade de tempo frente à crescente demanda e, ainda, o predomínio da visão biologicista ${ }^{14}$ de alguns peritos, muitas vezes, não é possível a troca de saberes que conforma o trabalho em equipe.

Como desafio extrainstitucional, destaca-se o insuficiente contato com a rede e com profissionais que atuam diretamente com os usuários. Essa interação nem sempre é possível devido ao acúmulo de funções/demandas no cotidiano profissional do Serviço Social nas mais variadas políticas públicas. A avaliação social do BPC é realizada mediante abordagem presencial com o usuário e, em casos específicos, através de visitas domiciliares/hospitalares. Para operacionalidade de seu trabalho e complementação de dados sociais imprescindíveis à conclusão da Avaliação Social, o Serviço Social do INSS encaminha aos assistentes sociais da rede a Solicitação de Informações Sociais/SIS, que nem sempre retorna, comprometendo a compreensão mais apurada da realidade relatada. Ao invés disso, a troca de informações com esses profissionais poderia fornecer dados esclarecedores sobre as condições de vida dos usuários e propiciar maior acesso através de análise conjunta de casos.

Ainda no que diz respeito à rede, a discrepância entre oferta de serviços e demanda dos usuários também se configura um limitador da ação profissional do assistente social no INSS, na medida em que, diante de uma realidade multifacetada permeada pelas múltiplas sequelas da "questão social”, nenhuma política pública sozinha é capaz de dar respostas mediatas ou imediatas às necessidades sociais. É necessária uma rede socioassistencial forte que seja capaz de operar a referência e a contrarreferência, procedendo com o seu objetivo de proteção social.

13 Na Gerência Executiva de Juiz de Fora/GEXJF, são nove assistentes sociais e aproximadamente sessenta médicos peritos.

14 Percebida na resistente visão de totalidade, especialmente após a introdução da determinação da limitação do usuário ser enquadrada como de longo prazo (uma decisão apenas médica que, em sua maioria, não considera o quesito "Atividade e Participação" que conjuga parte social e médica). 


\section{CONCLUSÃO}

O Serviço Social na Previdência Social se fortaleceu no final dos anos 2000 e a Avaliação Social do BPC configurou-se em uma de suas demandas mais consolidadas. A partir de sua inserção no processo concessório, foi possível construir uma visão de totalidade do sujeito demandante não apenas do benefício assistencial, mas também enquanto usuário da Previdência Social em interface com a Assistência Social.

Durante muitos anos, a profissão ficou restrita à orientação/informação dos benefícios previdenciários. Na atualidade, sua perspectiva educativa se amplia a partir da oitiva e interpretação das múltiplas histórias de vida, decodificando os domínios adotados pelo Novo Modelo de Avaliação Social na perspectiva de direito. Esse olhar sobre a realidade trouxe ao profissional um ângulo novo da "questão social" antes não percebido em profundidade: o da busca pelo acesso ao BPC como forma de sobrevivência por grande parte da população e não apenas pelos tradicionalmente considerados deficientes, em face do alijamento do mercado de trabalho e/ou cobertura previdenciária, convivendo com limitações/incapacidades para a vida independente e laboral.

Apesar do avanço da atuação do Serviço Social previdenciário, o profissional já notou o imenso desafio que tem pela frente para o desenvolvimento de um trabalho na ótica do usuário, pois, se a metodologia é nova (instrumento de avaliação social), as ideias pré-concebidas no âmbito institucional continuam as mesmas, rotulando o indivíduo como capaz de trabalhar, ainda que em atividades insalubres/desprotegidas dos direitos trabalhistas, não devendo permanecer sob tutela do Estado através de um benefício não contributivo.

Lançando um olhar sobre os (in)deferimentos de BPC, nas APS que compõem as Gerências Executivas do INSS, identifica-se certa dificuldade de alguns profissionais médicos em perceber a complexidade do domínio "Atividade e Participação" na concessão do benefício, desconsiderando que, baseado no conceito ampliado de saúde, o grau de vulnerabilidade social limita a participação. O Novo modelo de Avaliação traz esse domínio 
como análise igualmente fundamental como são os "Fatores Ambientais" e "Função do Corpo". Entretanto, ao subalternizá-lo, prevalece a visão centrada no corpo biológico, reforçando tanto o conceito restrito de saúde quanto de deficiência, alijando diversos segmentos do acesso.

Diante do impasse que se estabelece entre o ranço cultural do modelo biomédico e a nova conjuntura de análise, o Serviço Social encontra seu espaço de luta para garantia de direitos. Ao realizar uma leitura crítica do Novo Modelo de Avaliação, este é concebido ao mesmo tempo como um avanço dentro da discussão de acesso igualitário e também como um desafio, sendo necessário traçar estratégias e reflexões conjuntas entre os saberes das áreas médica e social para que divergências se unam pela busca de consenso. Ao lado dos desafios, o Serviço Social visualiza no trabalho interdisciplinar possibilidades de construção de parcerias que tomem as necessidades da população como referência, contribuindo para a mudança de paradigma, ampliação do acesso e uma assistência qualificada e humanizada.

\section{REFERÊNCIAS}

ABREU, M. M.; LOPES, J. B. O Plano Básico de Ação do Serviço Social no INPS - 1972: racionalidade técnica modernizadora no serviço assistencial da política previdenciária. In: BRAGA, L.; CABRAL, M. S. R. (Org). Serviço social na Previdência: trajetória, projetos profissionais e saberes. 3. ed. São Paulo: Cortez, 2008.

AGUIAR, A. G. Serviço Social e Filosofia: das origens a Araxá. São Paulo: Cortez, 1982.

ANTUNES, R. Os sentidos do Trabalho: ensaio sobre a afirmação e a negação do trabalho. 9. ed. São Paulo: Boitempo Editorial, 2007.

BEHRING, Elaine Rossetti. Brasil em contra-reforma: desestruturação do Estado e perda de direitos. São Paulo: Cortez, 2003.

BRAGA, L.; CABRAL, M. S. R. (Org.). o Serviço Social na Previdência: trajetória, projetos profissionais e saberes. 3. ed. São Paulo: Cortez, 2008. 
BRASIL. Lei n. 3.807, de 26 de agosto de 1960. Dispõe sobre a Lei Orgânica da Previdência Social. Brasil, 1960. Publicada no DOU em 05/09/160.

. Constituição da República Federativa do Brasil. Brasília: Gráfica do Senado Federal, 1988. Brasil, 1988. Publicada no DOU em 05/10/1988.

.Lei $\mathbf{n}^{\circ}$ 8213, de 24 de 1991. Dispõe sobre os Planos de Benefícios Previdenciários e dá outras providências. Publicada no DOU em 25/07/1991.

. Lei n 8742 de 07 de dezembro de 1993. Lei Orgânica da Assistência Social. . Publicada no DOU em 07/12/1993.

- Matriz teórico-metodológica do Serviço Social na Previdência. Brasília: MPAS, 1994.

. Decreto n.1.744, de 08 de dezembro de 1995. Regulamenta o benefício de prestação continuada devido à pessoa portadora de deficiência e ao idoso, de que trata a Lei n. 8.742, de 07 de dezembro de 1993, e dá outras providências. Brasil, 1995.

. Decreto n. 6.214, de 26 de setembro de 2007. Regulamenta o Benefício de Prestação Continuada da Assistência Social devido à pessoa com deficiência e ao idoso de que trata a Lei n. 8.742, de 07 de dezembro de 1993, e a Lei n. 10.741, de $1^{\circ}$ o de outubro de 2003, acresce parágrafo ao art. 162 do Decreto n. 3.048, de 06 de maio de 1999, e dá outras providências. Brasil, $2007 a$.

- Ministério do Desenvolvimento Social e Combate à fome (MDS). Avaliação de pessoas com deficiência para acesso ao Benefício de Prestação Continuada da Assistência Social: um novo instrumento baseado na Classificação Internacional de Funcionalidade, Incapacidade e Saúde. Brasília, DF: MDS, 2007b.

. Decreto n. 6.564, de 12 de setembro de 2008. Altera o Regulamento do Benefício de Prestação Continuada, aprovado pelo Decreto no 6.214, de 26 de setembro de 2007, e dá outras providências. Brasil, 2008. 
. Portaria Conjunta MDS/INSS n. 1, de 29 de maio de 2009. Institui Instrumentos para a avaliação da deficiência e do grau de incapacidade de pessoas com deficiência requerentes ao Benefício de Prestação Continuada da Assistência Social - BPC, conforme estabelece o art. $16, \S 3^{\circ}$, do Decreto n. 6.214, de 26 de setembro de 2007 , alterado pelo Decreto n. 6.564 , de 12 de setembro de 2008. Brasil, 2009

. Decreto $n^{\circ} 7.617 / 2011$. Altera o Regulamento do Benefício de Prestação Continuada, aprovado pelo Decreto no 6.214, de 26 de setembro de 2007.

- Memorando Circular Conjunto $\mathrm{n}^{\circ} 03$ DIRSAT/DIRBEN/ DIRAT/INSS de 30 de maio de 2011. Implanta as alterações na avaliação das pessoas com deficiência, para acesso ao Benefício de Prestação Continuada da Assistência Social - BPC, no SIAVBPC. Brasília, 2011b.

. Portaria Conjunta MDS/INSS nº1, de 24 de maio de 2011. Estabelece os critérios, procedimentos e instrumentos para a avaliação social e médico-pericial da deficiência e do grau de incapacidade das pessoas com deficiência requerentes do Benefício de Prestação Continuada da Assistência Social, revoga com ressalva a Portaria Conjunta MDS/INSS nº1, de 29 de maio de 2009, e dá outras providências. Brasília, 2011C.

. Memorando Circular Conjunto $n^{\circ} 31$ DIRBEN/PFE/INSS de 06 de julho de 2012. Explana sobre a decisão proferida na Ação Civil Pública $n^{\circ}$ 2009.38.00.005945-2. Desconsideração de outro BPC e de benefício previdenciário de valor mínimo na análise da renda per capita familiar. 2012.

CAVALCANTI, G. C. et al. Avaliação Social da Deficiência e do Grau de Incapacidade. In: CAVALCANTI, G. C (Org). Manual do Novo Modelo de Avaliação Social do Benefício de Prestação Continuada da Pessoa com Deficiência. Brasília: INSS, 2009.

CARTAXO, A. M. B. Estratégias de Sobrevivência: a Previdência e o Serviço Social. São Paulo: Cortez, 1995. 
. Seguridade Social e Projeto Ético-Político Profissional: desafios aos/às Assistentes Sociais na Previdência Social. 2010. Disponível em: <http://www.cfess.org.br/arquivos/slide_anacartaxo.pdf >. Acesso em: 8 abr. 2011.

CARTAXO, A. M. B.; CABRAL, M. S. R. O processo de desconstrução e reconstrução do projeto profissional do Serviço Social na Previdência: um registro de resistência e luta dos Assistentes Sociais. In: BRAGA, L.; CABRAL, M. S. R. BRAGA; CABRAL (Org.). Serviço social na Previdência: trajetória, projetos profissionais e saberes. 3. ed. São Paulo: Cortez, 2008.

CFESS. Conselho Federal de Serviço Social. Código de Ética do Assistente Social. Aprovado pela resolução CFESS n. 273/93. Brasília: CFESS, 1993.

. Histórico da Luta em Defesa do Concurso Público e de Condições de Trabalho para os/as Assistentes Sociais do INSS. CFESS, 2010. Disponível em: <www.cfess.org.br/arquivos/historico_defesaAS_inss.pdf>. Acesso em: 31 abr. 2011.

DINIZ, D.; SQUINCA, F.; MEDEIROS, M. Qual Deficiência? Perícia Médica e Assistência Social no Brasil. Caderno. de Saúde Pública, Rio de Janeiro: FIOCRUZ, v. 23, n. 11, p. 2589-2596, 2007.

FALEIROS, V. P. Tecnocracia e Assistencialismo no capitalismo autoritário. O Serviço Social na Previdência Social dos anos 70. In: BRAGA, L.; CABRAL, M. S. R. (Orgs.). Serviço social na Previdência: trajetória, projetos profissionais e saberes. 3. ed. São Paulo: Cortez, 2008.

FLEURY, S. A Seguridade Social Inconclusa. 2004. Disponível em: <http://www.11.fgv.br/ebape/nova-ebape/comum/arq/ Seguridade.pdf>. Acesso em: 4 abr. 2011.

GOMES, A. L. O Benefício de Prestação Continuada: Uma Trajetória de Retrocessos e Limites - Construindo Possibilidades de Avanços? In: SPOSATI, Adaílza (Org.). Proteção Social de Cidadania: inclusão de idosos e pessoas com deficiência no Brasil, França e Portugal. 2. ed. São Paulo: Cortez, 2008. 
GUEDES, C. R.; NOGUEIRA, M. I.; CAMARGO JR., K. R. A Subjetividade como Anomalia: contribuições epistemológicas para a crítica do modelo biomédico. Revista Ciência e Saúde Coletiva, Rio de Janeiro, v. 11, n. 4, out./dez. 2006.

GUIMARÃES, E. C. O Novo Modelo de Avaliação da Deficiência e do grau de incapacidade de fins de concessão do BPC e suas implicações no projeto ético-político do Serviço Social. Trabalho de Conclusão de Curso (Curso de Serviço Social) - Universidade de Brasília, Brasília, 2011.

IAMAMOTO, M. V. Serviço social em tempo de capital fetiche: capital financeiro, trabalho e questão social. São Paulo: Cortez, 2007.

IAMAMOTO, M. V.; CARVALHO, R. Relações Sociais e Serviço Social no Brasil: esboço de uma interpretação histórico-metodológica. 18. ed. São Paulo: Cortez, 2005.

INSS/DIRSAT. Instituto Nacional do Seguro Social/Diretoria de Saúde do Trabalhador. Manual Técnico do Serviço Social. Diretoria de Saúde do Trabalhador/DIRSAT. Março. 2012. Aprovado pela RESOLUÇÃO INSS-PRES N 203, DE 29 DE MAIO DE 2012. Diário Oficial da União, 30 maio 2012.

MARQUES, R. M.; MENDES, À. Os dilemas do financiamento do SUS no interior da seguridade social. Revista de Economia e Sociedade, Campinas, v. 14, n. 1, sup. (24), p. 159-175, jan./jun. 2005.

MOREIRA, M. C. O Serviço Social do INSS a partir da década de 1990: análise da implantação da Matriz Teórico-Metodológica. In: BEHRING; Elaine (Org.). Trabalho e seguridade social: percursos e dilemas. São Paulo: Cortez; Rio de Janeiro: FSS/UERJ, 2008.

MOTA. A. E. Cultura da Crise e Seguridade Social: um estudo sobre as tendências da previdência e da assistência social brasileira nos anos 80 e 90. 4. ed. São Paulo: Cortez, 2008. 
NETTO, J. P. Ditadura e Serviço Social: uma análise do Serviço Social no Brasil pós-64. 8. ed. São Paulo: Cortez, 2007.

OMS. Organização Mundial da Saúde. CIF: Classificação Internacional de Funcionalidade, Incapacidade e Saúde. In: BUCHALLA, C. M. (org. e coordenação da tradução). 1. ed. 1.reimpro. São Paulo: Editora da Universidade de São Paulo, 2008.

PEREIRA, P. A. A assistência social na perspectiva dos direitos: crítica aos padrões dominantes de proteção aos pobres no Brasil. Brasília: Thesaurus, 2006.

. Necessidades Humanas: subsídios à crítica dos mínimos sociais. 5. ed. São Paulo: Cortez, 2008.

SILVA, A. A. O Serviço Social na Previdência Social: entre a necessidade social e o benefício. In: BRAGA, L.; CABRAL, M. S. R. (Org.). Serviço social na Previdência: trajetória, projetos profissionais e saberes. 3. ed. São Paulo: Cortez, 2008.

SILVA, A. T. Os desafios da Avaliação Social para o Acesso ao BPC. Trabalho de Conclusão de Curso (Curso de Serviço Social) Universidade de Brasília - UnB, Brasília, DF, 2010.

SPOSATI, A. Benefício de Prestação Continuada como Mínimo Social. In: SPOSATI, A. (Org.). Proteção Social de Cidadania: inclusão de idosos e pessoas com deficiência no Brasil, França e Portugal. 2. ed. São Paulo: Cortez, 2008.

YAZBEK, M. C. O Serviço Social como especialização do trabalho coletivo. In: Koike, M. (Org.). Caderno de Capacitação em Serviço Social e Política Social. Módulo 02: Reprodução Social, Trabalho e Serviço Social. Brasília: CFESS - ABEPSS - CEAD/NED, 1999. 